\title{
Ueber Bau, Entwickelung und Eintheilung der Nieren-Geschwiilste
}

\author{
Yom \\ Privatdocenten Dr. Otto Busso, \\ I. Assistenten am Pathologischen Institut der Universităt Greifswald. \\ Hierzu Taf. VIII.
}

Die Nierengeschwülste sind wohl deshalb ein so bevorzugtes Arbeitsfeld für die histologische Forschung geworden, weil die Tendenz der modernen Geschwulst-Untersuchung, an Stelle des rein morphologischen ein genetisches Entscheidungs-Princip zu setzen, hier mit ganz besonderen Schwierigkeiten zu rechnen hat.

Der erste Schritt zu einer rationellen Eintheilung der Nierentumoren auf Grund einer einheitlichen Matrix ist von P. Grawitz ${ }^{1}$ ) im Jahre 1884 gethan worden, als er erkannte, dass eine grosse Zahl der bei Erwachsenen vorkommenden Nierengeschwïlste, deren Deutung bis dahin unmöglich war, von versprengten Theilen der Nebennieren ihren Ausgang nehmen, und den Bau der Nebenniere bezüglich der davon ausgehenden Geschwülste wiedergeben. Er fasste also die grosse Anzahl der oft sehr verschieden aussehenden Strumae suprarenales aberratae, oder, wie sie jetzt vielfach genannt werden ${ }^{2}$ ), der Hypernephrome zusammen, und gliederte sie aus der. grossen Masse der nach rein morphologischem Principe als Sarcome, Carcinome $u_{\text {. s. w. be- }}$

1) Dieses Archiv Bd. 93.

a) Centralblatt f. d. Krankheiten der Hara- und Sexualorgane Bd. 5. 


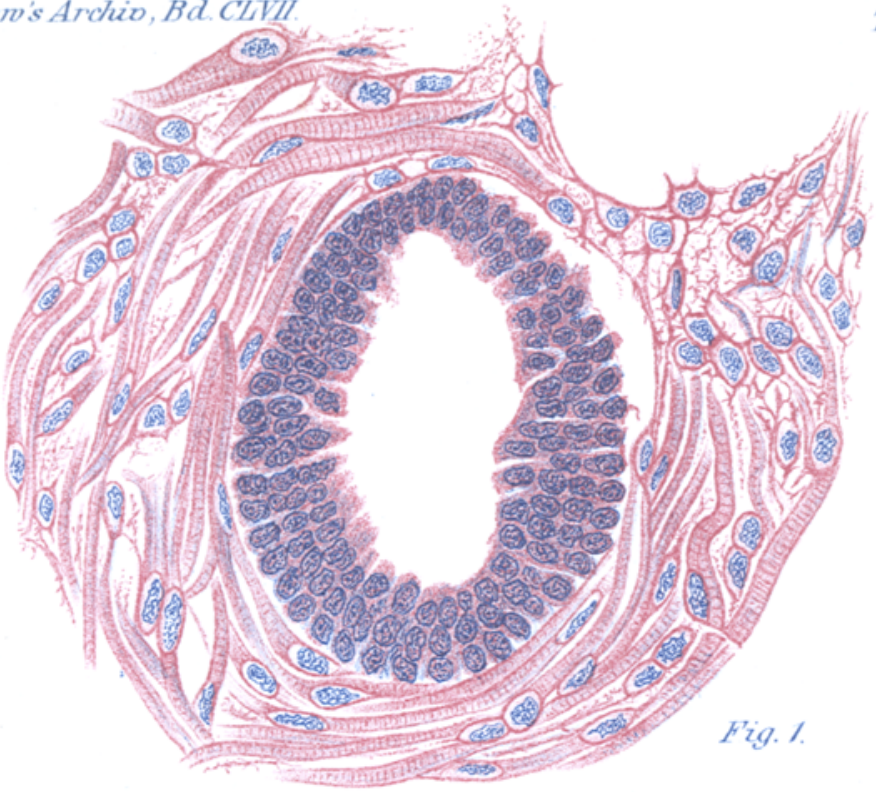

Tat. VIII.

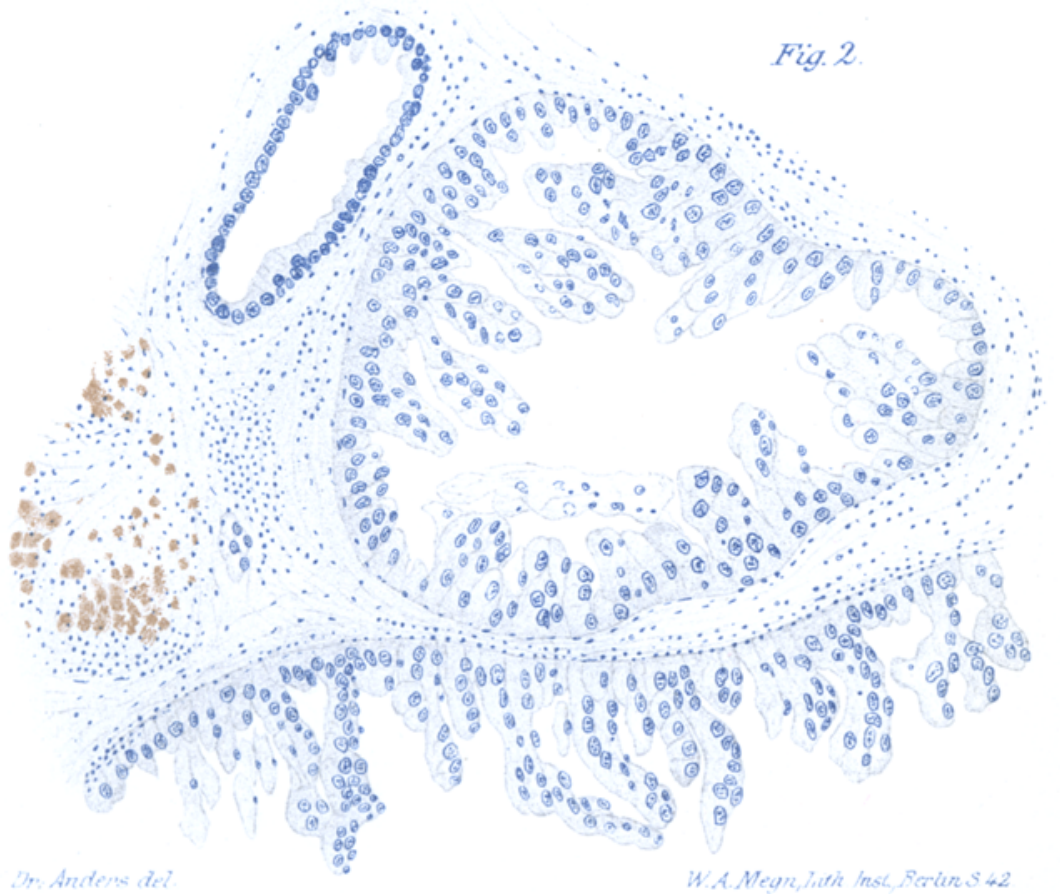


zeichneten Tumoren aus. Bis in die neueste Zeit standen aber diesen, auf die Genese als Eintheilungs-Princip zurückgeführten Geschwulstgruppe die grosse Mehrzahl der malignen Nierentumoren noch unvermittelt gegenüber. Erst im Jahre 1898 hat Birch-Hirschfeld ${ }^{1}$ ) aus diesen Geschwülsten eine zweite, in sich geschlossene, einheitliche Gruppe ausgelöst, die er unter dem Namen der "embryonalen Adeno-Sarcome" zusammengefasst hat, wobei auf besondere Eigenthümlichkeiten in Form und Structur weniger Gewicht gelegt wird, als auf das Princip der Entstehung der morphologisch sehr verschiedenen Geschwülste aus einer einheitlichen Matrix. Birch-Hirschfeld kommt zu der Erklärung, dass diese in versprengten Theilen der Urniere zu suchen sei. Schon lange Jahre vorher hat der Befund von quergestreiften Muskeln den Gedanken angeregt, dass auch diese Bestandtheile nur durch eine embryonale Keimverlagerung zu erklären seien.

Gerade auf diese Fragen gedenke ich im Folgenden näher einzugehen, und ich hoffe zur Lösung derselben einen nicht unwichtigen Beitrag zu liefern; dem entsprechend werde ich diejenigen Tumoren, welche mehr zum Zwecke des Vergleichs aufgeführ ${ }^{t}$ werden (Fibrome) oder sich nur durch besonders seltene Befunde auszeichnen (Myome) kürzer abhandeln, während ich die complicirten Tumoren, welche gleichzeitig typische und atypische Wucherungen von Epithel und Stroma, namentlich glatte und quergestreifte Muskeln, Knorpel- und Ganglienzellen enthalten, ausführlich beschreiben werde. Die principiell wichtigen Eragen über die Zusammengehörigkeit und über die eigentliche Matrix nöthigen mich, schon im Texte der Beschreibungen diesen Gesichtspunkten Rechnung zu tragen.

Ich lasse dann einige aus Nebennieren-Keimen hervorgehende Geschwülste folgen, worauf später eine Bearbeitung der Cystennieren den Abschluss bilden soll ${ }^{2}$ ).

1) Ziegler's Beiträge Bd. 24.

3) Ich glaube um so eher auf eine eingehende Besprechung der Literatur verzichten zu können, als dieselbe gerade in den letzten Jahren von den verschiedensten Autoren genau durchgearbeitet worden ist. Wer sich hieräber Aufklärung verschaffen will, den verweise ich auf 


\section{Eibrome der Niere.}

Bezüglich der tuberösen Fibrome ist kaum etwas Veues zu sagen; der Standpunkt, den Virchow in seinem Geschwulstwerk einnimmt, ist auch beute noch maassgebend für die Beurtheilung dieser kleinen, bindegewebigen Knötchen in der Marksubstanz der Niere. Wir sehen sie im Allgemeinen aneh heute noch als das Product einer interstitiellen Nephritis, als entzindliche Geschwälste an, die ohne klinische Bedeutung sind.

Bei mikroskopischer Untersuchung solcher Fälle findet man neben dem derberen Bindegewebe grössere oder kleinere Abschnitte von Schleimgewebe, und vielfach auch eine Beimengung von isolirt oder in Gruppen liegenden, schlanken Spindelzellen nit stäbchenförmigen Kernen, die unzweifelhaft glatte Muskelfasern darstellen. Immerhin ist die Zahl dieser Elemente so gering, dass es durchaus fraglich ist, ob dieselben dureh eine Vermebrung der normaler Weise in der Marksubstanz vorhandenen Muskelfasern entstanden sind, ob ihnen also eine active Betheiligung bei der Bildung dieser circumseripten, kleinen Ge. schwulst-Kuötchen zuzusprechen ist.

Anders ist dies dagegen bei den Geschwülsten, welche von der Nierenkapsel ausgehen. Diese besitzen vielfach einen so reichlichen Gehalt an glatten Muskelfasern, und zeigen auch sonst die Eigenschaften der aus fibro-musculärer Matrix hervorgehenden Geschwülste, dass man sie, von einzelnen Ausnahmen abgesehen, wohl richtiger zu den Fibro-Myomen als za den Hibromen rechnet.

In Folgenden will ich zwei Geschwülste dieser Art beschreiben, die nach mancher Richtung hin einen böchst bemerkenswerthen Befund darbieten.

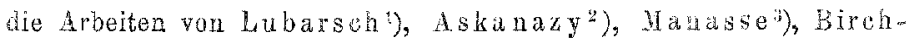
Uirschfeld, Freitag, Graupner ${ }^{4}$, Perthes ${ }^{3}$ ) und Strübing ${ }^{6}$ ).

) Dieses Archiv Bd. 136.

2) Zi egler's Beiträge Bd. 14.

3) Dieses Archiv Bd. 142, 143, 145.

*) Ziegler's Beiträge Bd. 24 .

) Deutsche Zeitschrift für Chirurgie Bd. 42.

6) Deutsehes Archiv f. klinische Medicin Bd. 43 . 
Fall 1.

Grosses Fibro Myom der Nierenkapsel einer 52jährigen Frau.

Krankenbericht:

Das Präparat ${ }^{1}$ ) entstammt einer 52 jährigen Frau, die schon vor 25 Jahren die Geschwulst in ibrer linken Seite bemerkt und in der ganzen Zeit ein sehr langsames Wachsen derselben beobachtet hatte. Später 'trat Schmerzhaftigkeit und Fieber ein, weshalb die Frau sich in das Krankenhaus aufnehmen und operiren liess.

Bei der Operation floss aus dem riesenhaften Tumor sehr viel blutige, etwas übelriechende Flüssigkeit. Die Geschwulst wog zusammen mit dem aufgefangenen Theile der Flüssigkeit $9 \mathrm{~kg}$, wobei $\mathrm{zu}$ bemerken ist, dass ein grosser Theil dieser Flüssigkeit bei der Operation nicht aufgefangen werden konnte, sondern verloren ging.

\section{Beschreibung des Präparates:}

Das Präparat, so wie es uns nach der Uebersendung vorliegt, besteht im Wesentlichen aus einer sehr grossen Cyste, an deren einen Seite noch ein Stück der Niere zu erkennen ist. Die Niere geht ganz allmäblich mit ibrer Kapsel in die Wandung der Cyste über, und zwar mit ihrer convexen Seite, derart, dass der Hilus der Niere an der äusseren Peripherie des Tumors gelegen ist. Die Wand der Cyste ist in den verschiedenen Theilen sehr verschieden dick. Ihre Innenfläche ist unregelmässig und entbält jakchig zerfallene und nekrotische Geschwulst-Abschnitte; beim Eingiessen von Wasser lässt sich dicke, schmierige, rothbraun gefärbte Flüssigkeit abspülen, und die mehr oder minder nekrotischen. Gewebsfetzen flottiren. Dabei zeigt sich, dass ein etwa faustgrosses, festes Stück in der Cyste, von allen Seiten losgelöst, freiliegt; dasselbe hat eine unregelmässige Oberfäche, fühlt sich rauh und hart, wie Bimstein an, und giebt beim Beklopfen mit dem Messer Metallklang. Auf der einen Seite ist die sehr feste Wand ebenfalls vielfach mit scharfrandigen, spitzen Kalkmassen incrustirt, die Dicke der Wand schwankt hier zwischen $1-3 \mathrm{~cm}$. Die äussere Oberfläche des cystischen Tumors ist glatt. Einige Fettläppchen, die bei der Operation aus der Nachbarschaft mit entfernt worden sind und der Gesehwulst aussen aufsitzen, lassen sich leicht von der Kapsel abtrennen. Auf der andern Seite ist die Wand erheblich viel dicker, misst auf dem Durchschnitt bis $8 \mathrm{~cm}$, und fühlt sich ganz ausserordentlich derb an. Auf der Innenseite springen hier knollenartig einige bis gänseeigrosse Knoten in das Lumen der Cyste vor. Dieser Theil der Cystenwand wird durch einen tangential zu derselben gelegten Schnitt so aufgeschnitten, dass man eine möglichst grosse Schnittfläche hiervon zur Anschaurng bekommt. Beim Aufschneiden

1) Das Präparat wurde mit einem kurzen Krankenbericht von Herrn Professor Bäckel, dirigirendem Arzt des Diakonissenhauses Bethanien in Stettin, am 1. April 1898 dem Greifswalder Pathologischen Institut eingesandt. Ich sage Herrn Professor Häckel dafür meinen verbindlichsten Dank. 
finden sich auch hier wieder kleinere Cyzten, mit theilweise verkalkten Wandungen oder mehr oder waniger frei bewegliehem, verkalkten Inhalt; die kleineren Cysten enthalten ausserdem entweder hellen, klaren oder trïben, zum Theil blutig gefäblen, zum Theil missfarbigen Inhalt. Im Grossen und Ganzen aber legt der Durchschnitt ein gleichmässig grauweisses Geschwulst-Gewebe klar, das in seinem Anssehen am meisten an Darchschnitte vou Wibro-Myomen des Uterus erinnert. Auch dio Schnite, dio etwa durch die in die Cyste hineinragenden Geschwulstinollen gemacht werden, liefern eine äbnlich anssehende Schnitfläche. Andere Theile dagegen bieten ein vollstïndig opakes Ausseben, wio os sich in nelrotischem Gewebe fadet. Auf Durchshnitten, die durch die düneren Stellen der Wand gelegt werden, sieht man aussen eine sebr derbe, feste Gewebslage won verschiedener Dicke, der innen noch deutlich erkennbare Reste von theils "gut erhaltenem, theils nekrotisch aussehendem Geschwulst-Gewebe anliegen.

\section{Mibrostopischer Befund.}

Schnitte, die von dem frischen Präparate angefertigt werden, zeigen in zartes, fibrilläres Gewebe, in dem die feinen Fasern, za Bündeln geordnet, sich in der mannigfaltigsten Art kreuzen. Bei Aufbellung mit Essigsäure treten lange, schlanke, stäbchenartige Kerne hervor; sie sind reibenförmig und zu Zügen angeordnet, die in sebr verschiedener Richtung das Gesichtsteld durchziehen. In Schnitten, die von den inneren Partien der Cyste genommen sind, bemerkt man eine nach dem Inneru zu inmer stäker werdende Fett-Metamorphose, derart, dass zuerst nur einzelne, meist lurch ihre Grösse ausgezeichnete Zellen verfettet sind, deren Zahl mehr und mehr zunimm, bis endlich in den innersten Lagen das ganze Gewebe total degenerirt ist. In diesen verfetteten Partien bemerkt man auch einige erweichte und halb vertüssigte Gebiete, in deren Bereich man grössere Fettropfen und Cholestearin-Krystalle antriffe Cholestearin-Kryitalle in grosser Anzabl gewinnt man auch aus der Flüssigkeit der kleineren und grosseren Cysten, daneben vielfach amorphes Blutpigment. Verschieden ist die Structur der einzelnen kalkhaltigen Abschnitte der Geschwulst. Bei der grösseren Anzahl derselben findet man einfach eine Ablagrerung feiner oder etwas grösserer, theils amorpher, theils krystallinischer Kalkmassen im Bindegewebe, dessen Structur nach Auflösurg des Kalkes deutlich hervortritt, hier handelt es sich also um Calcification. Im Gegensatz dazu zeigen einge andere kalkhaltige Stellen, schon bei sohwächerer Vergrösserung, statt der sonst angetroffenen Dunlselfarbung einen intensiven Glanz, und bei zusatz ron. Salzsäure treten vielfach verzweigte und anastomosirende Zellen vom Aussehen der Knochen-Körperchen bervor. Hier handelt es sich also um eine Motaplasie des Bindegewebes in Knochengewebe, um eine wirliche Ossification.

Die Untersuchung des gebärteten Präparates an gefärbter Schnitten bestätigte im Allgemeinen den am frischen Präparate gemachten Befund, 
ohne etwas wesentlich Neues darzubieten. Es möge vielleicht nur noch besonders hervorgehoben werden, dass das Verhältniss der Zellen zur Intercellular-Substanz recht beträchtlich schwankt. Im Grossen und Ganzen ist die Geschwnlst aber sehr arm an wirklichen Zellen; die fibröse Substanz prävalirt meistens sehr erheblich. Die an die Cyste grenzenden Abschnitte geben keine Kernfärbung, andere sind sebr stark mit Eiterzellen durchsetzt, hier liegt eine wabrscheinlich durch Eiter-Erreger hervorgerufene Entzündung vor, welche auch wohl das Fieber erklärt, das in den Tagen vor der Operation bestanden hatten.

\section{Epikrise:}

Es handelt sich also hier um ein Fibro-Myom der Niere, wie es in solcher Grösse nur einmal bisher beobachtet worden ist. Als Matrix desselben ist das fibro-musculäre interstitielle Bindegewebe der Niere selbst oder ihrer Kapsel anzusehen. Genaueres über den Ausgang lässt sich bei der ecormen Ausdehnung der Geschwulst nicht mehr angeben. Diese zeigt ganz und gar die Eigenschaften der Fibro-Myome anderer Organe, besonders des Uterus. Sie gleicht denselben in ihrem Bau makroskopisch, wie mikroskopisch, und verhält sich auch betreffs der Degeneration ganz wie diese. Es findet sich, wie so häufig, eine durch Blutungen complicirte Erweichung und Verflüssigung eines grossen Theiles der Geschwulst, derartig, dass dieser Abschnitt geradezu in einen dickwandigen Sack umgewandelt worden ist.

Die bei der Untersuchung der Flüssigkeit angetroffenen, sehr zahlreichen Cholestearin-Krystalle macken es höchst wahrscheinlich, dass die Geschwulst-'Theile durch Fett-Metamorphose zu Grunde gegangen sind. Andere Abschnitte zeigen aber sehr weitgehende Verkalkung, das ist ebenfalls ein Degenerations-Process, wie er sich in Fibro-Myomen sehr häufig findet. Aber nicht in diesem Verhalten liegt das Bemerkenswerthe des Falles, sondern vielmehr in der ganz enormen Grösse des ungeheuer langsam angewachsenen Tumors.

Kleinere Fibrome kommen ja öfter in der Niere zur Beobachtung, sie machen keine klinischen Erscheinungen, finden sich vielmehr als zufälliger Befund bei der Section. Die wenigen grösseren Fibrome dagegen, die bekannt geworden sind, sind unter ähnlichen Erscheinungen klinisch, wie anatomisch, verlaufen. So berichtet 
Tillmann ${ }^{3}$ ) tiber oinen 10 Kilo schweren Tumor der Nierenkapsel, den er bei einer $28 j a ̈ h r i g e n$ Patientin exstirpirt hat, und den or als ein Myxoma fibromatosum beschreibt. Dasselbe erwies sich ubrigens als bösartig, indem es sehr bald recidivirte nind den Tod der Patientin im Verlauf eines Jahres herbeiführte.

Auf dem Chirurgen-Congress 1885 demonstrirte $\mathrm{Clans}^{2}$ ) ein durch Operation entferntes Bibrom, welches sich zwischen Rindenund Markabstanz entwickelt, und in Folge von Blutung zur Bildung eines grossen, eystischen Hohlraumes gelïhrt hatte.

Ueber ein drittes Fibrom der Niere, das schon zu Lebzeiten Firscheinungen gemacht hatte, ist von Wilks s berichtet worden. Die Geschwulst hatte sich langsam, vielleioht in dem Zeitraum von zehn Jahren entwickelt, und war als allmählich wachsender Tumor seit vier Jahren mit Sicherheit palpirbar. Bei der Section zeigte sich, dass ein umfangreicher Knoten durch Verlegung des Ureters zu einer Hydronephrose geführt hatte. Der Tumor bestand aus sehr derbem, schwieligem Bindegewebe, ohne Beimengung von Krorpel $\mathrm{u}$. s. w.

Manasse' beschreibt ein grosses Venen-Endotheliom der Niere, in dessen Kapsel er derartig massenhaft glatte Muskelfaserm, zu Bändern uod Zügen geordnet, angetroffen hat, dass er der Vermuthung Ausdruel giebt, es möchte sich daboi vielleicht um ein sarcomatös degenerirtes Myom handeln. Doch vermeidet er, dies als sicher hinzastellen.

Aus dem Mitgetheilten ist ersichtlich, dass der hier beschriebene Tumor thatsächlich seines Gleichen in der Literatur kaum hat.

Fall 2.

Wibro-Myoma strio-cellalare der Nierenkapsel einer 57 juhrigen Frau.

Krangenbericht: Das Präparat stammit von einer 57 Jahre alten Frau, welche seit ungefähr einem Jahre eine in der letzten Zeit rasch an

1) Tillman. Exstirpation einer von der linken Niereakapsel ausgehenden, zehn Kilo wiegenden Geschwulst. Hygia 1891, Seite 277 bis 285.

2) Claus: Verhandlungen der Deutschen Ges. für Chirurgie 1885.

3) Wilks: Fibrous tumour of the kidney. Transactions of the pathological Soc. 1870. XX. S. 224.

) Manasse: Zur Histalogie und Histogenese der primären Nierengeschwälste. Dieses Arch. Bd. 143, S. 306. 
Grösse zunøbmende Geschwulst in der rechten Seite bemerkte. Beschwerden waren gering und bestanden nur in zeitweilig auftretendem Druckgefühl. Urin war in Menge vermehrt, und hin und wieder stark eiweisshaltig. Es war häufig Brechreiz vorhanden, und konnte auch durch Druck auf die Geschwulst ausgelöst werden. Das Colon ist nach der Medianlinie verdrängt und vor dem Tumor gelegen. Der allgemeine Ernäbrungs- und Krăftezustand befriedigend.

Am 3. November 1895 wird durch Hern Geheimrath Helferich in Chloroform-Narkose die rechte Niere mit einer daransitzenden Geschwulst entfernt. Dabei wird die Vena cava ascendens angerissen; das Loch wird durch Ligatur geschlossen. Die Frau entleerte seitdem nur noch wenige Cubikcentimeter Urin. Der Tod trat zwei Tage später ein.

Bei der Section fanden sich keine Metastasen in anderen Organen, die linke Niere war gesund.

Beschreibung des Präparates:

An der zum grössten Theil noch erbaltenen Niere sitzt am unteren Ende eine grosse, ungefähr kugelige Gescbwulst von etwa Kindskopfgrösse; die Oberfäche ist leicht höckerig, indem grössere und kleinere Protuberanzen sich vordrăngen. Die Geschwulst lässt sich. leicht von dem sie umgebenden Fettgewebe abtrennen; beim Aufsehneiden sieht man, dass die Niere durch die Gesebwulst stark comprimirt ist, der Ureter ist verengt, und daber in Folge der Harnstauung das Nierenbeeken leicht erweitert. Die Capsula fibrosa der Niere lässt sich leicht und obne Substanzverlust abziehen. Hierbei bemerkt man, dass die Geschwulst innerhalb der Kapsel selbst zur Entwicklung gekommen ist; es hat sich gewissermaassen zwischen zwei Blättern der Capsula fibrosa die Geschwulst entwickelt, deren eines und äusseres die Gescbwulst aussen überzieht, wăhrend das andere als Septum zwischen Niere und Tumor sich einschiebt. Auf der Schnittfläche siebt man, dass die Geschwulst sich aus einzeInen Knollen und Lappen zusammensetzt; es ziehen zwischen den einzelnen grösseren Knollen bindegewebige Septen hindurch; die grösseren Gescbwulstknoten wieder sind in kleinere Bündel verwandelt. Der ganze Tumar bietet durchaus das Aussehen eines Fibro-Myoms, wie solche typisch in der Uteruswand vorkommen. Die Maasse der etwa kugeligen Geschwulst sind etwa $11 \mathrm{~cm}$ in der Länge, 12 in der Breite und 10 in der Dicke.

Mikroskopischer Befund: Bei der Untersuchung des frischen Präparates fanden sich an Zupfpräparaten lange, spindelförmige Zellen mit einem feinen, körnigen Protoplasma und ovalen oder länglichen Kernen. Auf Schnitten durchkreuzen sich die zu Zügen geordueten Zellenreiben nad bilden oft förmliche Wirbel. Auf Essigsäurezusatz gleicht das Bild völlig den Schnitten, die man aus Myowen des Uterus gewinnt. Bei Durchsuchung einiger weicherer Stellen finden sich grössere, spindelförmige ProtoplasmaBänder mit mehreren Kernen, deren Zellleib oft deutliche Querstreifung erkennen lässt. Diese Querstreifung ist in einzelnen grossen Zellen, am 
deutlichsten in unmittelbarer Nacbbarschaft des grossen ovahen Kerns ausgeprägt, in anderen tritt sie dagegen in den entfernten Ausläufern schärfer hervon. Bei weiterem Suchen trifft man auch wirliche Muskelfasern wit parallel verlaufenden Contouren und sehr zarter Querstreifung an. Die Untersuchung des gehärteten Objectes bestätigt die am frischen Präparate gemachten Beobachtungen. Die Geschwnlst zeigt in allen Theilen den Bau eines Myoms, dessen einzelne Abschnitte sich in der Hauptsache nur durch verschieden reichliche Beimengung des Bindegewebes unterseheiden. Gewisse Partien sind so zollenreich, dabei die Kerne noch so wenig gestreckt, dass sie fast sarcomatos aussehen; an anderen Stellen findet sich zartes Sohleingewebe.

Die Grösse der Zellen wechselt ganz ausserordentlich, In einzelner, zumal den derberen, bindegewebsreichen Partien liegen sebr kleive, protoplasma-arme Zellen mit schmalem, langgestrecktem Kern. Andere Geschwulstabschnitte bestehen aus grösseren, sehr viel breiteren Elementen, deren Kerne auch mehr oval und bläschenförmig sind; endlich findet man ganz erheblich viel grössere Protoplasma-Bänder mit mehreren, reihenförmig gelegenen Kernen, die zum Theil eine fast cubische Gestalt baben, und offenbar auch bedentend zahlreicher sind, als die schlanken, stäbchenförmigen Kerne. Die Anordnung der grossen Zellen ist dieselbe, wie die der kleineren, auch hier sind Züge und Reihen gebildet, die sich in allen Richtungen durchflechten. Wendet mar nun Oel-Immersion an, so sieht man in einigen dieser grossen Zellen eine sebr zarte Querstreifung; sie tritt vielfach am dentlicbsten in numittelbarer Näbe der Kerne hervor, seltener zeigen die Ausläufer eine besser ansgeprägte Querstreifung, als die centralen Abschnitte. Die quexgstreiften tellen liegen entweder solixt zwischen den grösseren glatten Muskel-Elementen, oder sie sind auch in. Bündeln angeordnet, die in Richtung und Verlauf dem Gesammtbilde sich einfügen. Hier, in den in Gruppen zusammenliegeaden quergestreiften Elementen findet man einzelne, vollständig quergestreifte askelfasern mit parallelen Grenzlinien, whintend die grosse Mehrahl vou ihnen jo eigentlich nur als ganz oder theilweise quergestreifte, grosse Spindelzellen bezeichnet werden können.

\section{Epilrisis:}

Die hier beschriebene Geschwulst hat sich innerbalb der Kapsel der Niere entwickelt und ist ihrem Baue nach als ein Fibro-Myom zu bezeichnen. Von dem gewöhnlichen Befunde der Fibro-Myome abweichend ist die verschiedenartige Entwickelung der einzelnen Muskelfasera. Wir finden neben gewöhnlichen schlanken Zellen mit langen Kern und reichlicher fibrillärer Intercellular-Substanz sehr zellenreiche Abschnitte mit kürzered, spindelförmigen Zellen und ovalen Kernen, und endlich excessiv grosse Elemente, wie wir sie sonst eigentlich nur im schwangeren 
Uterus antreffen. Diese Zellen sind wohl zehnmal so gross, als die gewöhnlichen glatten Fasern. Es hat also hier ein Wachsthum der Geschwulst nicht nur in Folge einer Vermehrung, sondern auch in Folge des Auswachsens und der Vergrösserung der einzelnen Elemente stattgefunden. Diese Vergrösserung ist offenbar als eine höhere Weiter-Entwickelung der Muskelfasern aufzufassen. Dieser Punkt erscheint nicht besonders wunderbar; auffällig ist aber, dass einzelne von den Zellen auch eine Querstreifung um den Kern herum oder in den Ausläufern erkennen lassen, ja, dass sogar vollständige Muskelbänder sich vorfinden. Ich will an dieser Stelle nur die Thatsache constatiren, dass quergestreifte Muskelfasern vorhanden sind, und dass sie nach Lage, Aussehen und Anordnung sich dem Systeme der glatten Muskelfasern als modificirte Elemente anfügen.

Die Annahme, dass hier eine Metaplasie vorliegt, ist die näcbstliegende, die natürliche; die Auffassung, dass die quergestreiften Zellen etwas von den umgebenden glatten absolut und principiell Verschiedenes, dass sie etwas Fromdartiges sein sollen, erscheint mit den beschriebenen Bildern kaum vereinbar. Ich werde auf die Frage, ob Metaplasie, ob Keim-Verlagerung, später, nach Beschreibung anderer Tumoren mit quergestreiften Muskelfasern, noch zurückkommen.

Ich möchte noch einmal auf das Alter der Patientin aufmerksam machen. Quergestreifte Muskelfasern in den Geschwülsten bei älteren Individuen gehören zu den allergrössten Seltenheiten.

Embryonale Adeno-Sarcome.

Ich gehe nunmehr über zu einer grossen Klasse von Nierengeschwülsten, die sich fast ausschliesslich bei Kindern innerhalb der ersten Lebensjahre entwickeln. Sie sind charakterisirt durch eine ganz eigenthümliche Vermischung von Wucherungs-Producten epithelialer und bindegewebiger Elemente. Das Mischungsverhältniss kann ganz ausserordentlich verschieden sein, und deshalb werden die betreffenden Geschwülste in der Literatur je nach dem Praevaliren des einen oder des andern Bestand theiles als Carcinome, Adenome oder Sarcome, oder als Adeno-Sarcome beschrieben. Sehr häufig sind in derartigen Tumoren quergestreifte Muskel- 
fasern anzutreffen, oder Theile von Knorpel oder Schleim-. gewebe, und das Vorkommen dieser in der Niere normaler Weise nicht vorhandenen Gewebsarten hat vielfach das Interesse der Untersucher in dem Maasse absorbirt, dass sie die daneben vorliommenden Drüsenschläuche vollständig vermachlässigt haben. Erst in neuester Zeit ist, wie schon in der Einleitung erwähnt, durch Birch-Hirschfeld auf die eigenthümliche Combination von Abkömmlingen der Epithelien und der Bindesubstanzen aufmerksam gemacht worden. Er hat diese Geschwulstgruppe unter dem Namen der ,embryonalen Adeno-Sarcome" zusammengefasst, und sie als eine einheitliche Kategorie den sonst in der Niere vorkommenden Goschwülsten gegeaübergestellt. Mir war die erste, von Döderlein und Birch-Hirschfeld im Centralblatt für die Erkrankungen der Harn- and Geschlechtsorgane publicirte, hierher gehörende Arbeit entgangen; ich war ohne ihre Kenntniss an die Untersuchung der folgenden 6 , von Kindern stammenden Geschwälste herangetreten, und hatte mich meinerseits za der Erkenntniss hindurchgearbeitet, dass diese im Kindesalter auftretenden Nierengeschwülste einen einheitlichen Typus darstellen, der sein Paradigma im embryonalen Gewebe habe, als die zweite ausführliche Arbeit ${ }^{1}$ ) erschien, in der Birch-Hirschfeld seine obige Ansicht noch einmal klarlegt und mit eingehenden Beobachtungen belegt. Birch-Hirschfeld führt diese Geschwülste auf Theile der Urnieren-Anlage zurück, die in die Niere versprengt und nuv hier weiter fortgewuchert seien. Ich dagegen glaube, das Prototyp dieser Tumoren in der embryonalen Niere selbst gefunden zu haben, und werde versuchen, bei der nun folgenden Beschreibung der dieser Gruppe angehörenden Nierentumoren für meine eigene Deutung Begründungen zu erbringen.

$$
\text { F } a \perp 13 .
$$

Embryouales Adeno-Myosarcoma eines 5jährigen Knaben.

Krankenbericht: Die Eltern bemerkten ira Oktober 1895 bei dem Kuaben eine Anschwellung der linken Bauchgegend, die allmählich an Grösse zunahm, und ferner, dass zweimal Blut dem Urin beigemischt war. Bei der Aufnahme in die Greifswalder Chirurgische Universitätsklinik am 15. November war der Patient in gutem Ernährungszustand. Die linke Seite prominirt unmittelbar unter dem Rippenbogen stärker, als die rechte,

i) Zieglex's Beiträge $\mathrm{Bd} .24$. 
auch schimmern dort grosse Venen durch die Haut, und es lässt sich -ein Tumor palpiren, der $5 \mathrm{~cm}$ vom Nabel entfernt ist, unten bis zur Spina anterior superior ossis ilei, hinten bis zur Wirbelsäule reicht, und oben hinter dem Rippenbogen verschwindet. Die Oberfäche ist anscheinend glatt, auf derselben liegen Darmschlingen, die leicht verschieblich sind. Im Urin keinẹ pathologischen Beinengungen. Am 18. November wird durch Herrn Geheimrath Helferich die linke Niere mit einem grossen Tumor exstirpirt. Dabei wird constatirt, dass die Vena cava vom Tumor vollständig umwachsen, bezüglich durchwachsen ist. Der Heilungsverlauf war gestört, die Hautnähte schnitten sämmtlich durch. Am 8. Dezember traten Oedeme der Beine, des Scrotum und des Penis, sowie Erbrechen auf.

Am 11. Dezember wird der Patient auf Wunsch der Eltern mit starken Oedemen entlassen. Geschwulstknoten im Abdomen sind nicht palpirbar. Exitus letalis trat Ende Januar 1896 ein. Section ist nicht gemacht worden.

Beschreibung des Präparates:

Das Präparat stellt eine grosse, kuglige Geschwulst dar, an deren oberem und unterem Ende noch je eir Stückchen Nierengewebe zu erkennen ist. Nach dem Aufschneiden drängt sich der unter einem starken. Druck befindliche Tumor weit äber die Schnittfäche hervor, wäbrend die Nierensubstanz im Verbältniss dazu sich weit zurückzieht. Auf diese Weise kommt sowohl am oberen, wie am unteren Ende des kugeligen Tumors ein Stückehen des Nieren-Beckens zur Anschanung, dessen Wände durchaus glatt sind; die Scbleimbaut ist buckelförmig vorgewölbt, die Calices sind stark erweitert. Die Geschwulst ist somit in dem mittleren Theil der Niere entstanden, ist gegen die Convexität der Nieren-Rinde, noch stärker aber gegen den Hilus hin. gewachsen. An der Convexität hat er die Nieren-Oberfläche durchbrochen und liegt direct unter der Nierenkapsel, die Oberfläche ișt leicht höckerig, indem kleinere, bis haselnussgrosse Knoten. sich halbkugelförmig erheben. Die Geschwulst setzt sich aus vielen Einzelknötchen zusammen, welche durch zahlreiche Septa von einander getrennt sind. Am Hîlus liegen, offenbar das benachbarte Gewebe durchsetzend, eine ganze Anzahl weiterer Geschwulstknoten, die bis hühnereigross und von dem eigentlichen Haupt-Tumor getrennt sind. Eine eigene Kapsel trennt den Tumor nicht von der Niere, die Geschwulst geht vielmehr ganz unregelmässig und allmätlich, die Nieren-Rinde mehr und mehr verdünnend, in dieselbe z̈ber. Die Consistenz ist etwas prall, aber doeh weich, die Farbe ziemlich gleichmässig graurosa. Die Geschwulst ist $11 \mathrm{~cm}$ lang, $12 \mathrm{~cm}$ breit und $10 \mathrm{~cm}$ dick.

Bei der mikroskopischen Untersuchung erweist sich der Tumor als eine Mischgeschwulst, an deren Zusammensetzung die versehiedensten bindegewebigen und epithelialen Elemente betheiligt sind. Die letzteren treten dort, wo sie am höchsten entwickelt sind, als schön ausgebildete Drüsenschläuche mit einschichtigem Cylinderepithel und verhältnissmässig grossem Lumen auf. Andere Canäle lassen dagegen eine mehrfache 
Sehichtung des Epithels erkerinon, die sowait gehen kann, dass ein eigenthiches Lumen gar nicht mehr gebldet wird, sondern die Gylinderzellen mit ihren Oberfachen direct zusammenstossen, die Kerne finden sich gewöhnlich im basalen Theile der Zellen. Dann wieder findet raan Felder von Epithelien, die regellos nubeneinander liegen. Sehr zahreiche Kerntheilungs-Figuren, die übrigens anch in den Epithelien der Drüsenschlâuche nicht fehlen, zoigen an, dass hier eine besonders lebhafte Wucherung der Epithelien in Gange ist. Beil dieser dichten Aneinanderlagerung der Zellen geht die Gylinderform vollständig verloren, nir hier ond da bemerkt man noch aus dem Zusammenschlasse und der Lagerung der Zellen die Tendenz, auch jetzt noch Dräsenschläuche zu bilden. Gar nicht selten trifft man Canäle, die anf der einen Hälfte ron einer einschichtigen Lage eylindrischer odor cubischer Zellen, at der andern jedoch von regellos gelagerten Zellhafen begrent werden. Mit einem Worte, wir finden alle Uebergänge rom hoch entwickelien Adenom bis zu dem typischen Carcinom. An letzteren Stellen ist die Abgrenzung gegen das Bindegewebe nicht überall deutlich erkembar, denn auch im Stroma findet sich hier ganz gewönlich eine sehr reichliche Kern-Anhäufung, und dio dicht xusammentiegenden jungen Birdegewebszellen sind nicht allemal von den jungen protoplasma-armen Epitbelzellen scharf zu unterscheiden. An den Stellen jedoch, wo höber entwickelte Epithelzellen liegen, ist auch fast ausnahmsios das Stroma hoter entwickelt. Hier haben sich dio jungen Bindegewebszellen meistens, unter Bildung zarter fibrilarer Zwischensubstanz, zw Spindelzellen ausgewachsen, die dani, zu Zügen geordnet, die Drüsenschläuche oft in mehrfachen concentrisch geschichteten Reihen umgeben. An andoren Stellen liegt verhältnissmissig hernarmes, fibroses Gewebe mit reichlicher Intercelinlar-Substanz. Weder andere Absehnitte onthat ten Züge und Zellreihen, die unzweifelhafte glate Muskelfasern sind. Diese durchflechten sieh genan wie in Myomen, oft nageben sie wie eine Muscularie die Oxüsensebläuche, docb derarb das die Epithelien onne Bildug einer Tunica propria direct der glatten 4 hiselfasern anfsitzen. Dort, wo eine reichlichere Anhäufung dieser bochentwicketen contractilen Elenerite stathat; firdet wan bäufig lang ausgeagene grosse spindelzellen, deren Protoplasm die ersten Anfänge von Lảngs- und Quer. shreifung, besonders in der Ungebung der Kerne, ertenen lässt. Daneben sieht man aber auch wirkliche, sehön ausgebildete, quergestreifte Muskelfasen. Dieselben sind schwaler und kernreicher. als die somatische Musculatur ron dreijährigen Kindern, sie zeigen fine Anordnang, wie die benachbarte glatte MIusculatur, ihre Bündel bilden of ile Fortsetzing der glatten Muskelzige. Man triffit die quergestretten Muskelfasern bald einzelin in mohr wereher, myxomatöser oder fibrom mscularer Substanz, oder aber zu grossen Lagern geordnet an. Auffallig ist dass ach zwischen und in den Lagen der quergestreiften Muskelfasern Ephthelien zu finden

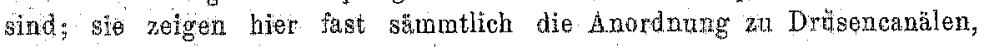
deren webrere gemblalich dicht bei einander liegen. Wieder bilden hier 
dann die quergestreiften Muskelfasern in mehrfachen concentrischen Reihen geordnet eine Art von Muscularis um die Drüsengänge, ähnliçh wie an andern Stellen die glatten Muskelfasern (Taf. VIII Fig. 1). Auch den quergestreiften Fasern liegen die Epithelien ganz direct auf, eine bindegewebige Grenze oder eine Basalmembran ist nicht vorhanden. Die Basis der Cylinder-Epithelien liegt ganz unmittelbar der Längsseite der Faser an. Es sind dies so eigenartige Bilder, wie man sie wobl kaum wieder zu sehen bekommt. Es sei bemerkt, dass solide Epithelnester in diesen Muskellagern nicht gelegen sind, und dass umgekehrt in dem Stroma der wirklich krebsigen Stellen sich weder quergestreifte, noch auch glatte Muskelfasern finden; das Stroma besteht hier vielmehr aus einem zellenreichen, sarcomatösen Gewebe. Es zeigt sich also, dass ein gẹwisses gleiches Verbältniss in der Entwickelungshöhe des Epithels und Stromas an allen Stellen besteht. In der Nähe der wenig entwickelten, sehr schnell wachsenden Krebszellen findet sich unreifes, fibro-musculäres Gewebe, dort, wo wir hobe Entwickelungs-Stufen des Gewebes in Gestalt von glatten und quergestreiften Fasern antreffen, haben auch die Epithelien den Höhepunkt ihrer Entwickelung erreicht, und bilden wohlgefügte, ein- oder mebrschichtige Drüsenschläuche. In diesen offenbar langsamer wachsenden Bezirken liegen auch zwei mikroskopisch kleine Inseln von hyalinem Knorpel, die von mehreren Lagen derben, kernarmen Bindegewebes umsponnen werden. Der Knorpel zeigt nicht das Aussehen von byalinem Knorpel Erwachsener, sondern ist viel reicher an Kernen und ärmer an Intercellular-Substanz, d. b. er entspricht embryonalem Knorpelgewebe.

Ich möchte an dieser Stelle noch erwähnen, dass ich ferner im Bindegewebe grosse, protoplasmareiche Zellen mit grossem, rundem Kern und auffallend grossen Kernkörperchen angetroffen habe, die zum Theil mit langen Fortsätzen versehen sind und böchst wahrscheinlich $G_{a n g l i e n-}$ zell en darstellen.

Wichtig für die Beurtheilung der Frage, wie und von welchen Theilen der Tumor entstanden ist, sind die Bilder, die man von der Grenze der Geschwulst zu der Niere erhält. Nähert man sich von der normalen Nierenrinde allmählich der Geschwulst, so bemerht man einmal eine Ausdehnung und Anfüllung der Harncanälchen mit Blut oder Lymphe, zum andern fällt eine allmähliche Verbreiterung des interstitiellen Gewebes auf. Die Dickenzunahme der Septen wird hauptsächlich durch immer reichlichere Lagen von Spindelzellen geschaffen, denen sich in der Nähe der Mark. substanz Züge glatter Muskelfasern beigesellen.

Da eine Kapsel an keiner Stelle ausgebildet ist, da ferner die Epithelien und Drüsenschläuche der Geschwulst zum grossen Theile den Epithelien und Harncanälchen völlig gleichen, und auch die Verändering des interstitiellen Gewebes ganz allmählich vor sich geht, so ist eine wirklich scharfe Grenze überhaupt nicht vorbanden; der Uebergang von Niere za Geschwulst vollzieht sich vielmehr ganz unmerklich. 
Epiorise: Der rorliegende Tumor stellt sich als oine Mischgeschwulst dar, die, wie besonders die Grenzabschnitte zeigen, aus der Niere selbst hervorgegangen ist, und $z$ war betheiligen sich an der Bildung des Tumors die Epithelien und das interstitielle Gewebe der Niere in gleicher Weise. Die Abkömmlinge der Harncanälchen-Epithelien erscheinen in der Geschwulst in den langsam wachsenden Stellen als cylinderformige oder cubische Epithelzellen wieder, die in einfacher Lage die Wand eines Canals bilden. Bei lebhafterer Wucherung entstehen Gänge mit mehrschichtigem Epithel, oder aber ungeordnete Haufen polymorpher Epithelien, die nur an verenzeltan stellen die Tendenz Hohräume zu bilden, erkennen lassen.

Von besonderem Interesse ist das Verhalten des Stromas. Dasselbe enthält ausser hochentwickeltem, kernarmem Bindegevebe, sarcomatöses und myxomatöses Gewebe, ferner ambryonalen, hyalinen Knorpel und glatte oder quergestreite Musculatur. Dabei liegen die unreifen Gewebsarten in der Nachbarschaft der Rrebsnester, während die hoshentwickelten Gewebe das Stroma der Adenom-ähnlichen Partien abgeben. Es zeigt sich somit, dass hier ein Theil der Niere in ge. schwulstartige Wucherung gerathen ist, wobei eine Bevoraugung entweder des Parenchyns oder des interstitiellon Gewebes nicht 2 n erkennen ist. Beide Theile sind in ganz gleicher Weise betheiligt. Gebt in einem Abschnitte der Geschwulst das Wachsthum langsam vorwärts, so wächst sowohl Epithel, als auch das interstitielle Gewebe langsam, und beide lassen ihre Elemente zu hohen Entwicklungs-Stufen heranreifen. Dann entstehen schöne Sohlauche und glatte oder quergestreifte Muskelfasern, oder knorpelige Bestandthelle. Besteht hingegen in anderen Abschnitten lebhafte Wucherung der Geschwulst-Elemente, so ist an dieser rapiden Vermehrung wieder wpithel und Stroma in ganz glelater Woige botheiligt, und liefert die unceifen Gewebstypen deg Cureinome mit sarcomatöser Zwischensubibanz.

Besonders hervorgehoben za. werden verdient noch das auch von mir abgebildete, höchst merkwürdige Misohungs-Verhältaiss von Epithel and Muskelfasora. Die hohen glindrischen Zellen sitzen den Seitenwänden der quergestreiften Fasern vielfach direct auf, theilweise umspinnen die quergestreiften Fasern die 
Drüsenschläuche, wie z. B. die Theca folliculi etwa den Graaf'schen Follikel einhüllt. Beachtenswerth ist auch, dass die quergestreiften Muskelfasern einzeln oder in Gruppen durch den ganzen Tumor verstreut vorkommen. Wenn wirklich die Muskeln durch Versprengung von Theilen der Urwirbelplatte in die Nieren bineingelangt wären, so würde man mit Recht erwarten müssen, dass die spätere Wucherung des hypothetisch angenommenen Muskelkeimes einen zusammenhängenden Knoten, oder mehrfache, von den hypothetischen Keimen anderer Abkunft räumlich getrennte Heerde innerhalb des Tumors bilden müsste.

Fall 4.

Embryonales Adeno-Sarcom der rechten Niere eines dreijährigen Mädchens.

Krankenbericht.

Das Kindchen soll von klein auf einen stark aufgetriebenen Leib gehabt haben, in Alter von einem halben Jahre ist ein hühnereigrosser Tumor in der rechten Seite zu fühlen gewesen. Seit Februar 1898 wurde ein Wachsthum der Geschwulst bemerkt, seit Mitte Juli, angeblich im Anschluss an eine längere Wagenfahrt, trat sehr schnelle Vergrösserung ein. Da innere Medication erfolglos ar, wso wurde Patientin in die Greifswalder Chirurgische Universitătsklinik am 12. August 1898 aufgenommen. Hier fand man das Abdomen stark aufgetrieben, besonders auf der rechten Seite fand sich ein kindskopfgrosser, harter Tumor, mit glatter Oberfiäche, der unverschiebbar die ganze rechte Lumbalgegend einnimmt und nach unten bis ins kleine Becken, nach oben bis unter den Rippenbogen reicht. Der Urin enthält Spuren von Eiweiss, sonst nichts Abnormes.

Am 15. August 1898 wird durch Laparatomie von Herm Geheimrath Helferich die Geschwulst der rechten Niere mit dieser entfernt. Die Wunde wird primär bis auf eine kleine Stelle, in die ein Jodoform-Tampon eingelegt wird, verschlossen, heilt primär; irgend welche Störungen im Heilungsverlaufe tratein nicht auf. Patientin entleert den Urin spontan und wird Ende September geheilt entlassen.

Beschreibung des Präparates:

Die Geschwulst ist von ovaler Gestalt, $19,5 \mathrm{~cm}$ lang, $13,5 \mathrm{~cm}$ breit und etwa $9 \mathrm{~cm}$ dick. Die Oberfläche ist im Ganzen glatt, und überall von. einer Kapsel äberzogen, die allmählich in die Capsula fibrosa der Niere selbst übergeht. An einzelnen Stellen drängen sich kugelige, bis gänseeigrosse Knoten vor. Die Gestalt entspricht im Ganzen der Nierenform, es findet sich ein deutlich ausgeprägter Hilus. Hier findet sich ein Ureter, der sich in der Dicke eines Gänsefeder-Kieles an dem Tumor entlang nach unten zieht, und sich oben zu dem Nierenbecken erweitert. Die Schleimbaut ist glatt und an keiner Stelle, weder- im Becken, noch in den 
theilweise ərweiterten Kelchen, von Geschwulstgewebe durchbrochen. Am oberen Pole ist noch ein nicht unbeträchtliches Stück Niere erhalten, das sich durch Aussehen und faserige Consistenz von dem sonst sehr weichen Tumor unterscheidet. Der grösste Theil dieses Nierenrestes liegt vor dem Nierenbecken, während sich hinter demselben hauptsächlich die Gesch wuIst entwickelt hat. Auch in dem noch erhaltenen Nierengewebe orkent man sehr zahlreiche, circumscripte Geschwulstkmoten won wechselnder Grosse. Die Capsula fibrosa lässt sich von der Niere in der Hauptsache ohne Substanzrerlust abziehen; nur an den Theilen, in denen die Geschwulstknoten die Obertlache der Rinde erreichen, hat eine Verwachsung mit der Bindegewebs-Kapsel derart stattgefunden, dass hier das Abziehen derselben nicht ohne Substanzverlust möglich ist. Auch an dem Frupt-Tumor bestebt ein gleich inniger Zusammenhang zwischen Kapsel und eigentlichem Geschwulst-Gewebe. Die Consistenz der Geschwulst im Grossen und Ganzen ist durchaus weiss. Die bei weitem grössten Theile der Geschwulst sehen opak aus, und sind entweder verfettet, oder gar vollständig nekrotisch. Nur an einzelnen Stellen der. Peripherie trifft man Lappen oder Knollen der Geschwulst ron glasigem, fischfleisch-ähnlichem Ausseben. KJeinere Abschnitte, die entweder an die absere Kapsel grenzen, oder in der Nachbarswhaf oder im Bereiche der noch erhaltenen Niere gelegen sind, zeichnen sich durch bedeutend festere Consistenz vor der Hauptmasse der Gesehwulst ans.

Bei der mikroskopischen Untersuchung des frischerı Präparates trifft man in den gut erbaltenen, nicht degenerirten Theilen denselben übereinstimmenden Befund. In Zupf-Präparaten sieht man sehr viele, verhältnissmässig kleine Kerne vam endothelialen Typus und kugeliger oder avaler Gestalt. Die Mehrzahl derselben ist nur von sehr kleinem Zellleibe umgeben, daneben findet man allerdings auch vereinzelt grössere Rundzellen mit entsprechend grösserem Kerne und ein oder zwei Kernkörperchen. Eine besondere Anordnung zu Zügen u. s. w. ist in Schnitten nur ausnahmsweise in circumskripten Bezirken zu erkennen. An keiner Stelle der in ihren versehiedensten Theilen durchsuchten Gesehwulst findet sich olwas, was an Knorpel oder quergestreifte Muskelfasern erinnert. Die derberen Partien des Tumor enthalten, im Gegensatz zu der Hauptmasse der Geschwulst, reichliche fibrilläre $\mathrm{Z}$ wischensubstanz

Im höchsten Maasse überrasehend gestaltete sich die Untersuchung des grebärteten und gefärbten Präparates, weil die verschiedenen Theile der Gesehwulst sehr differente Biider geben, deren Verständniss ein eingehendes Studium erfordert. In den centralen Partien findet man grosse Nester von Zellen, die durch relativ kernarme Septen von einander getrenpt sind. Die Zellen sind so protoplasma-arm, dass man eigentlich nur dicht anieinander gedrängte ovale Kerne sieht, jedermann würde nach solcher Stelle den Tumor eimlach für ein alveolüres Sarcom halten. In anderen Theilen sind diese Zellnester bedeutend lileiner, uud die binde. 
gewebigen Septa dementsprechend breiter und reichlicher. Wieder andere zeigen dagegen vollkommene Adenom-Struktur. Mit diesen Bildern wollen wir die Beschreibung beginnen, man erhält sie besonders dann, wenn man die an die Niere angrenzenden Partien der Geschwulst untersucht. Die Niere selbst enthält in der Rindensubstanz eine mächtige Anhäufung kleinerer Rundzellen im interstitiellen Gewebe; dadurch sind die Septen zwischen den gewundenen Harncanälchen mächtig verbreitert, diese selbst somit stark auseinander gedrängt. Die Querschnitte der gewundenen Harncanälcben nehmen mit der Annäherung an den Tumor an Grösse $a b$, bis sie schliesslich ganz versehwinden, die Glomerili gehen ebenfalls zu Grunde, indem eine fibröse Entartung und Scbrumpfung der Gefässschlingen zugleich mit einer Dickenzunahme der Bowman'schen Kapsel einhergebt. Allmählich nimmt der Zellenreichthum wieder ab, und man kommt an eine relativ zellarme, bindegewebige Kapsel der Geschwulst, in der aber längs und quer getroffene Epithelschläuche mit intensiv färbbaren Kernen auffallen. Von dieser Kapsel gehen, wie dies ja auch schon makroskopisch zu sehen. war, Stränge in die Geschwulst, und theilen die Geschwulst in einzelne Lappen, die sie einerseits umkleiden, andererseits wieder in kleinere Theile und Läppehen zerlegen. Schliesslich bilden sie in den alveolär aussehenden Theilen das. Stroma. In anderen Abschnitten der Geschwulst aber verbreitern sich diese bindegewebigen Abschnitte, dabei nimmt der Zellenreichthum erheblich zu. Sehliesslich bekommt man vollständig sarcom-ähnlich aussehendes Stroma zu Gesicht. Dichtgedrängt, nur durch feinste fibrilläre Substanz getrennt, findet man zahlreiche, vielfach za Zügen geordnete Spindelzellen. Diese sich vielfach durchflechtenden Züge von langgestreckten Zellen mit langen, stäbchenförmigen Kernen, gleichen ganz und gar den Bildern, wie sie Schnitte durch Uterusmyome liefern. In den weichen Geschwulst-Theilen, in denen sich schon makroskopisch ein an Schleingewebe erinnerndes Aussehen zeigte, findet sich diese Vermuthung durch die mikroskopische Untersuchung bestätigt. Hier ist sehr reichliches Schleingewebe mit prachtvollen, anastomosirenden Spindel- und Sternzellen gebildet. Trotz sorgfältigster Durchsicht der verschiedensten Schnitte lassen sich weder in dem fibrösen, noch in dem șarcomatösen, noch in dem myxomatösen Theile irgend welche Elemente auffinden, die für quergestreifte Muskelfasern oder knorpelige Substanzen gehalten werden können.

Sehen wir uns nun einmal den Bau des Alveolen-Inhaltes bezüglich der Zellen näher an. Sie unterscheiden sich sofort durch die intensiv gefärbten Kerne von den in den Septen liegenden bindegewebigen Elementen. Dort, wo sie im Centrum der Geschwulst zu grösseren Haufen zusammenliegen, kann man über ihre Dignität kein Urtheil gewinnen. Um über ihre Abstammung ins Klare zu kommen, muss man wieder die an die Niere grenzenden Theile der Geschwulst aufsuchen. Hier fallen, wie schon oben erwähnt, in der relativ derben, bindegewebigen Kapsel und den 


\section{4}

grösseren Septen längs and quer getroffene drüsenăbnliche Canäle auf, die von einer einschichtigen Lage versehieden hoher, epithelialer Zellen wit intensiv farbbaren Kernen ausgekleidet sind. Am Rande der Kapsel nehmen diese Epithelschläuche an Menge zu, während zugleich das Bindegewebe in demselben Masse abnimmt. Je weiter man nun in die Geschwulst hiveingelangt, desto mebr ändert sich das Verhälitniss zwischen den bindegewebigen Theilen und den Abkommlingen der Epithelien au Gunsten der letzteren. Und zwar kommt, wie mir scheint, diese VerSchiebung des Verhältnisses anf zweierlei Weise zu Stande. Erstens: Die Wpithelien wochern ungeheuer, onne dass überall wirthiche Drüsentumina gebildet werden, es kommt dabei vielnehr zur Buldug breiter, solider Zellzapfen, denen man of ihr Herrorgeber aus den drusigen, wit Lumen versehenen Schänchen noch daran ansehen kann; dass vielfoch bet einem solchen Drüsenschlauch nur die eine Seite noch ron einer eixschichtigen; cylindrischen Zellenlage begrenzt ist, während an der anderen ein grosserer, solider Zelhaufen die Wand der Drüs bildet; anf der enen Sute is also noch die Drüsenwand als solche wa sehen wâhrend sie auf der anderen Seite schon krebsig degeneturt ist. Bei Durchsicht ener grösseren Zahl ron Präparaten trifft man thatsächlich alle Uebergänge won den erst entstehenden, zu don wohlausgebildeten, za den lrebsig entateten Epithelschläuchen und den völlig carcinomatös aussehenden Abschnitter. Sobald die Anordhung der Zelien at Drüsen verloren gebt, geht auch die cylindrische Gestalt verloren; die dicht nebea einander gedrangten Zellen sind protoplasmamarm, vom Zelleib ist oft so gat wie gar nichts wahrzunebmen. Ton ainer bestimmten Anordnung der Zellen in den Nestern ist nichts za bemerken, nur bier und da siebt atan, wenu man dureh die anderen Theile aumerisam geworden ist, noch eine gewisse Tendenz der Zellen, Drủsenschläuche zu bilden. Sie lagern sieh dan zum Treise um cin helleres Contrum zusammen; die Keme diesen hellen sind of etwas stärer gefarbt, als die anderen, und fallen daher schon bei Anwendung schwächerer Vergrösserungen auf.

Zweitens: Etwas verschieden von diesen im Grossen und Ganzen regallos zusammenliegenden Zellhaufen sind andere Nestef, in denen eine gewisse papilläre Anordnung der Zellen sofort in die Angen fallt. Diese Zelnester entstehen anf eine andere Art, indem nehulloh die Drüsenschläuhe in die Gewebs-Spalten eindringen und darin weiterWuchern. Hierbei drängen sich die Epitbelien in immer feinere Saftlücken hinein, die bindegewebigen Septen werden immer feiner and zarter and schwinden endich ganz, so dass dann die Fiphelreihen unmittelbar neben einander zu liegen kommen, und nut die papillär angeordneten Zellhanfen formiren. Diese Art der Entstehnog wird durch vielfache Vebergangsbilder wahrscheinlich gemacht. Die Form der Zellen passt sich den Waehbarschaft an. Bei sebr lebhafter Wucherung wird nur "assersti wemig Protoplasna gebildet. 


\section{E p i krise.}

Somit ist der vorliegende Tumor als eine Geschwulst der Niere zu betrachten, an deren Aufbau Parenchym und interstitielles Gewebe in gleicher Weise betheiligt ist. Letzteres liefert die Kapsel und das Stroma der alveolären Geschwulst, und tritt uns entweder als verhältnissmässig zellarmes, derbes Faserge webe, oder von dem 'Typus zellreicher Sarcome, oder als Schleimgewebe entgegen. In den kernreichen Stellen findet man zumeist Spindelzellen, die zu Zügen geordnet sind, und oft so lange, schlanke, stäbchenförmige Kerne haben, dass sie als glatte Muskelfasern angesehen werden müssen. Das Epithel ordnet sich in der Geschwulst entweder. zu regulären Drüsenschläuchen, oder bildet Zellnester, wie in Carcinomen.

Fall 5.

Embryonales Adeno-Myosarcom der Niere eines vierjährigen Knaben.

Krankenberieht.

Der vierjährige, bis dahin gesunde Knabe begann im August 1894 über Schmerzen in der linken Seite zu klagen, zugleich liess der Appetit nach. Mitte November bemerkten die Eltern eine Geschwulst im Bauch. Bei seiner. Aufnahme in die Chirurgische Universitätsklinik zeigte der kräftig entwickelte, etwas anämische Knabe einen stark aufgetriebenen Leib, besonders auf der linken Seite. Im linken Epigastrium ein kopfgrosser Tumor von derber Consistenz, der vorn bis zur Mittellinie, nach

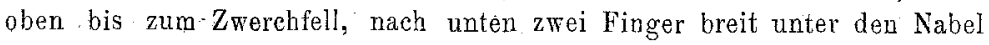
reicht und nicht verschieblich ist. Vorne, nahe an der Medianlinie, fühlt man das Colon descendens. Im Urin mässiger Eiweissgehalt. Der Urín kann spontan nicht entleert werden, sondern wird durch Katheterismus bis zum 25. November entfernt. Die Menge beträgt $200 \mathrm{ccm}$ pro die. Am 26. November kann der Harn wieder spontan gelassen werden, dabei nimmt der. Eiweissgehalt ab.

Am 28. November 1894 wird die linke Niere mit einer grossen Geschwulst von Herrn Gebeimrath Helferich exstirpirt. Die Geschwulst war theilweise mit dem Peritonaeum so fest verwachsen, dass ein Stück desselben mit entfernt werden musste.

In den ersten beiden Tagen nach der Operation trat Erbrechen ein, der Urin ging unwillkürlich ab. Dann besserte sich das Befinden schnell. Am 12. Januar 1895 ist die Wunde vollständig geschlossen. Patient wird nach Hause entlassen. $\mathrm{Zu}$ Hause verschlechterte sich sein Allgemeinbefinden, und es trat am 29. März 1895 der Tod ein. Eine Section ist nicht gemacht worden, 
Beschreibung des Präparates. An dem etwa kindshopfgrossen Tumor ist noch ein grosses Stück Nierengewebe erhalten; die Geschwulst selbst hat sich aus dem untersten Theile der Niere heraus entwickelt, die Capsula fibrosa lässt sich von der Niere leicht abziehen, geht aber dann in die Geschwulst über. Die Goscbwulst ist seh" woild, man fält schon beim Palpiren von aussen eine grosse Menge Cysten; beim Autschneiden Aliesst aus einer ganzen Reiho derselben heller, wässeriger Inhalt horaus. Die Geschwalst ist zum Theil diffus in die Nachbarschatt hineingewuchert, und geht, wie auf der Schnittlache zu sehen, gamz alluählich in die Niere über.

Die Geschwulst misst etwa $9 \mathrm{~cm}$ in der Länge, $14 \mathrm{~cm}$ in der Breite und $10 \mathrm{~cm}$ in der Dicke. Auf der Schnittfäche treten zahlreiche Lücken und und Spaiten in sehr verschiedener Grösse hervor. Die Consistenz der einzelnen Lappen ist weich, vielfach schwammähnilich. Einzelne Partien sehen roth aus, und sind offenbar nekrotisch, andere haber ein scbönes, rosafarbenes Aussehen. Andere bekommen durch die vielen Spalten das Anssehen, wia beim Sarcoma phyllodes, als ob man dureh einen Kohlkopf hindurobshnitte.

Das Praparat wiegt $1205 \mathrm{gr}$.

Mikroskopischer Befund. Schon bei der frisehen Untersuchung werden sehr schöne, quergestreifte Muskelfasern in grosser Menge aufgefunden. Bei der Untersuchung gebärteter Schnitte wird zunaichst constatirt, dass die massenhatten Cysten und Spalten grosse, erweiterte Lymphrăume sind, die mit einer dünnen, feinen Endothel-Auskleidung versehen sind. Dí Hauptraasse der Geschwulst zeigt übereinstimmend alveolären Bau. Die Alveolen sind sehr verschieden gross, ebenso ist das dazwischen gelegene Gewebe in sehr wechselnder Masse ausgebildet. Es besteht zum allergrössten Theile aus einem verbältnissmässig kernarmen Gewebe mit ganz ausserordentlich zarter, fibrillärer Zwischensubstanz. In den Maschen der Fibrillen befindet sich Lymphe, die zu einem feinsten Faserwerk geronnez ist. In der Nähe der Lymphgefässe nimmt der Kerngehalt zu, das Gewebe scheint weniger zart, es findet sich auch festere IntercellularSubstanz. Die Zellen sind zunächst spindelförmig, die Kerne oval, gegen die Mitte der kernreichen Abschnitte rücken die Zellen dichter aneinander, sie sind protoplasma-arm, von polyedrischer Gestalt. Intercellular-Substanz findet sieh hier nicht. Zuweileu haben sich die Zellen im Contrum der kermreichen Inseln zu drüsenähnlichen Schläuchen zusammengelagert, dann zeigen sie deutliche cubische oder cylindrische Formen. In eimigen grossen Zellanhäufungen trifft man Stellen, die wie Adeno-Carcinom aussehen. Hier begegnet man ganz ähnlicben Bildern, wie sie in Tumor No. 4 beschrieben worden sind. Da Nester solcher Drutsencanäle in den verschiedensten Theilen der Geschwulst anzutreffen sind, so kann kein Zweifel darüber bestehen, dass sie nicht die normaler Weise vorhandenen und auseiandergedrängten Harncanälchen der Niere sind, sondern wirk- 
Jich neugebildete Drüsenschläuche darstellen. Oft trifft man auch bier wieder Stellen, in denen die Zellen sich so massenhaft und schnell vermehrt haben, dass es dabei nicht mehr zur Ausbildung von Drüsencanälen kommt, sondern vielmehr Epithelnester, wie im richtigen Carcinom, gebildet werden. Dabei ist es dann auch wieder schwierig, vielfach sogar ganz unmöglich, die Grenze zwischen Epithelien und Bindegewebszellen festzustellen. In dem Stroma verstreut finden sich sebr zahlreiche Züge glatter Muskelfasern, unter denen sich sehr vielfach grössere Zellen mit theilweiser Querstreifung befinden. Neben diesen, immerbin nur vereinzelt auftretenden quergestreiften Muskelfasern enthält nun aber der Tumor an mehreren Stellen grässere Nester von Haselnussgrösse mit quergestreiften Muskelfasern, und zwar in einer Grösse und einer Breite, wie ich sie sonst in keiner Geschwulst wieder angetroffen babe. Wieder ist die Anordnung der quergestreiften Fasern genan dieselbe, wie die der glatten im Uterus oder in Leiomyomen. Wieder finden sich innerhalb der Nester oder in unmittelbarer Nähe schön entwickelte Drüsenschläuche. Besonders reichlich finden sich die Epithelnester an einer Stelle in unmittelbarer Nähe der Niere. In diesem Falle ist, wie sich im mikroskopischen Präparate zeigt, die Ge. schwulst durch eine Art Kapsel von der Niere abgegrenzt. Man sieht, wie in der Nachbarschaft des Tumors in der Niere eine bedeutende, bindegewebige Vèrdickung des interstitiellen Gewebes besteht. Je näher man der Geschwulst kommt, um so mehr nimmt das Bindegewebe zu, und um so kleiner werden die Harncanälchen und ihre Epithelien. Schliesslich findet man mehrere, concentriscb um die Geschwulst herumlaufende Bindegewebs-Lamellen mit langen, parallel verlaufenden Reihen sehr dünner, langer Kerne, wie sie sich etwa im Sehnengewebe finden. Diese Bindegewebslagen stellen offenbar die Kapsel der Geschwulst dar. Jenseits derselben findet man die oben geschilderten Bilder.

\section{Fall 6.}

Embryonales Adeno-Myosarcom der linken Niere eines sechsjährigen Knaben.

Krankenbericht. Der sonst gesunde sechsjährige Knabe klagte im Sommer 1897 über Schmerzen in der linken Lendengegend, später bemerkte man eine sich langsam entwickelnde Geschwulst. Er wird am 8. December 1897 in die Greifswalder Chirurgische Universitätsklinik aufgenommen. Im linken Epigastrium fühlt man eine bis zur Mittellinie reichende, etwa kindskopfgrosse Geschwulst, die die Lendengegend stark nach aussen vorwölbt, sich sehr derb anfühlt, beim Betasten nicht schmerzhaft und fast unverschieblich ist. Urin wird spärlich entleert, ist frei von pathologischen Beimengungen

Am 10. December exstirpirt Herr Geheimrath Helferich die linke Niere mit dem daransitzenden Tumor; die Wunde, die primär genäht worden war, muss in den nächsten Tagen, einer heftigen phlegmonösen Entzündung wegen, wieder geöffnet werden, sie reinigt sich ganz allmäblich; 
die Linmenge steigt ton 290 ecm bis zu 1560 cern. Joch stell sich am 7. Januar Fieber ein, der Palient wird somnolent, verfallt mehr und metr und wird am 19. Januat auf Wunseh seiner Eltern in fast maribunden Zustande nach Hause entassen, wo denn auch bald der Tod erfolgt.

Eine Section ist nichr gemacht warden.

Beschreibung des Praparates.

bas von der Uhirurgischen Kinilk übersandte Präparat des offenbar atuserst malignen Tumors ist zam grossen Theil noch ron Gewebe überkleidet, dem man seine Abstammang rom Nierengewebe noch unschwer ansiaht. Nur mit grosser Mähe läss sich noch ein grösseres Stïck nnveranderter Miereasubstanz mit erweitertew Becken, abgefuchten Paphlen und danner Rindenschicht aufinden, das dem unteren Pol der Viere entspricht. Hier fndet sich auch noch ein Stuck des Ureters, der ebenso, wie das Mierenbeden, von Gesehwilst-Gewebe im Grossen und Ganzen frei ist. An dem Nierengewebe fallen einzelne bräunlich gefärbte Abschnitte auf. Nach Abziehen der Nerentapsel erkenn man denticher, als vorter, dass die Geschwulst an einzelnen Stellen des Nierengewebe durchbrochen hat und frei zu Tage liegt. Die Gesehwulst misst $14: 16: 14 \mathrm{~cm}$.

Am Hilus der Niere lagern grössere Gescbwulsknoten nit unregelmansigen, zura Theil zerfetzter Oberfäche; sie ragen aus der Niere heraus, und stenen mit der Tumor, wie sich besonders auf der Schnitffache dentlich zeigt, in directen zusamenhange. Die unregglmässige Gestaltang der Oberfach kommt offenbar daher, dass der Tumor nicbt vollständig entfernt werden konnte, sondern die Trennung in den Tumor selbst entstanden ist. A uch her in desen Tumor siebt man auf der Schnittfäche, dass sich derselbo aus mahtreichen grösseren und klemeren Lappen zusammensetat, die dureb derbe, bindegewebige Septa ron einander getrennt sind Auf der Schnittäche bemerkt man viele nebratische Abschnitte, andere sind hämorhagiseb fnefitrirt.

\section{Mikroskopische Untersucbung.}

In irsehen zupfpräparaten, die von den weissen, festeren Theilen der (reschwulst angefertigt werden, sieht man Spindelzellen mit ovalem Kern und zartem, körnigem Protoplasma und vereinzelte breitere Fasern wit sehr zarter Querstreifurgg; die glasig durchscheinenden, weichen Abschnitte des Tumors bestehen aus Schleiwgewebe.

Diese Beobachtung wird bei Untersuchung des gehärteten Präparates lurchans bestätigt. Man tindet sehr grosse, kernarme Abschnitte wit weicher, schleimiger $Z$ wischensubstan\%, in der die vielfach anastomosirenden spindelund sternfömigen Zellen liegen. Mit diesen kertarmen Bezirken wechseln kleinere, kernteichere Stelien ab. Der Uebergang ist ein allmählicher. Die peripherischen Thuile der zellenreichen Gebiete entbalten zwischen den Spindelgellen wit ovalem Kerne noch fibröse Zwischensubstanz in wechselnder Menge. Gegen die Mitte zu nimmt sowohl die Intercellularsubstana, als 
auch die Grösse der Zellen ab, man findet schliesslicb nur noch dicbt aneinander gelagerte runde Kerne. Oft liegen djeselben ganz regellos dichtgedrängt neben einander, meistens jedoch zeigen die central gelegenen Zellen eine deutliche Anordnung zu schönen, manchmaI verschlungenen oder verzweigten Drüsenschläuchen. Einige Schläuche entbalten um ein sehr grosses Lumen eine Lage von prachtvollen, hohen Cylinderzellen mit basal gestelltem Kerne, im Lumen befindet sich feiner Detritus. An anderen Stellen haben sich dagegen die Zellen zwar auch schon zu kleinen, cubiscben Zellen differenzirt und um ein Centrum herum gelagert, aber es ist noch nicbt zur Bildung eines wirklichen Lumens gekommen, sondern die so angeordneten Zellen stellen sich auf Längs- und Querscbnitten noch als solide Stränge dar. Sehr gross ist auch hier wieder die Schwierigkeit, zu entscheiden, welcher Art die unmittelbar angrenzenden Zellen sind.

Die peripherisch in dem Zellhaufen gelegenen sind sicher bindegewebiger Abkunft, die im Centrum sind ebenso sicher Epithelien, und zwar nicht nur diejenigen, die die Drüsencanäle formiren, sondern auch die unmittelbar daran angrenzenden. Es ist aber unmöglich, genau und sicher zu bestimmen, wo das Bindegewebe aufhört und die Epithelien anfangen.

In der weichen, myxomatösen Substanz verdienen noch zweierlei Dinge unsere Aufmerksamkeit. Das eine sind breite Bänder weicher protoplasmatischer Substanz, die sich mit Eosin und Pikrin sehr leicbt und intensiv färben, und an einigen Stellen deutlich feine Querstreifuug erkennen lassen. Sie verlaufen bier meistens vereinzelt, nur selten findet man sie zu Zügen geordnet. Auch zahlreiche glatte Muskelfasern sind in dem Sçhleimgewebe zu sehen, auch sie verlaufen meistens isolirt. Ausser den breiten quergestreiften Muskelbändern sieht man nun zweitens rundliche Figuren, die sich genau so färben, wie die quergestreiften Muskelfasern, und zum Theil wohl unzweifelhafte Querschnitte derselben darstellen. Diese zeigen vielfach einen, oft excentrisch gelagerten Kern. Nun giebt es aber viel grọssere, runde Körper mit zwei, drei, vier, ja fünf Kernen, die unmöglich als Querschnitte der Fasern aufgefasst werden können; dafür sind sie viel zu gross; sie gleichen aber, nach Lichtbrechungs- und Färbungsvermögen, ganz evident den Muskelfasern, und zeigen wie diese auch reichlichen Glykogengehalt. Marcband1) beschreibt diese Gebilde näher und bildet sie auch ab, erklärt sie als aus contractiler Substanz bestehend, gewissermaassen als missbildete, kugelige Muskelfasern. Ich kann mich seiner Erklärung nur anschliessen. Auch ieb batte den Eindruck, dass es sich hier; um etwas, den Muskelfasern in chemischer Substanz nahestehendes oder gleichartiges bandelt.

Ich kann mich dem Eindrucke nicht verschliessen, dass von allen untersuchten Nierengeschwülsten die vorliegende die allerunreifsten EntwicklungsStadien in sämmtlichen Geweben darbietet. Das Schleimgewebe ist äusserst weich und zellarm, Bindegewebszellen und Epithelien zeigen in den

1) Dieses Arch. Bd. 100. 
Wucherungs-Gebieten gänzlich indifferente Formen, und die Bänder contractiler Substanz lassen aueh sebr wenig deutliche Querstraifung erkennen.

Epikrise:

Die beiden vorsteß̉end beschriebenen Geschwülste eines dreijährigen und eines sechsjährigen Knaben bieten so viel Uebereinstimmendes, dass wir dieselben am besten gemeinschaftltch betrachten. Wir treffen hier den schon in den anderen Nierengeschwülsten beobachteten Typus wieder. An dem Aufbau der Mischgesehwulst betheiligen sich epitheliale, bindegewebige und musculöse Elemente. Es scheint mir die natürlichste Erklärung, anzunehmen, dass als Matrix der Geschwulst eben wieder ein ganzer Abschnitt der Niere mit allen ibren Bestandtheilen anzusehen ist. Die Epithelien der Harncanälchen liefern entwedor Epithelrohre oder solide Epithelzellhanfen; zallreiche Kerntheilungs. Figuren beweisen aukh in den hoch entwickelten Epithel. rohren, dass diese winlilich bei der Bildung der Geschwulst neu entstanden sind, und nicht etwa eiufach die ursprüngliohen, durch Sarcom-Wucherung auseinandergedrängten Harncanälchen darstellen. Mit anderen Worten, das Epithel der Harncanälohen ist auch activ an der Bildung der. Tumoren betheiligt, die in den Fällen allerdings zum weitaus grösseren Theile aus den Abkömralingen des interstitiellen Gewebes aufgebaut sind: dazu gehören die sehr grossen Abschnitte von Schleimgewebe, das den Haupt-Bestandtheil der Geschwülste bildet, dann die kleineren etwas festeren Knoten von Sarcom-Gewebe, and endich die musculösen Bestandtheile. Dabei begegnen wir wieder der Thatsache, dass die Wucherungs-Bezirke im Bindegewebe in engster Wechselbexiehung zu denjenigen der Epithelien stehea, die fast ausnahmslos im Centrum dieser Knötchen zu finden sind.

Eine kurze Erörterung verlangt noch das Verhalten der musculösen Elemente. Beim Vergleiche der Bilder aus den verschiedentlichen Tumoren bietet sich allerdings eine seln erhebliche Verschiedenheit dar. Marchand, Pernica, Ribbert und Wolfens berger geben an, dass die quergestreiften Muskelfasern in deg Geschwälsten nur die Formen und Verhälnisse wiedergeben, die bei der Bildung der quergestreiften Musculatur im embryonalen Gewebe sich vorfinden. Ribbert und Wolfensberger ziehen aus diesem Verhalten den Schluss: Weil die 
Muskelfasern nur die bei der Entwickelung der Embryonen volkommenden Bilder darbieten, und weil in der EntwickelungsGeschichte glatte Musculatur und quergestreifte Muskelfasern unabhängig von einander aus getrennten Keimen entstehen, so sind die quergestreiften Fasern in den Geschwälsten nur als $\mathrm{Ab}$ kömmlinge verlagerter Keime quergestreifter Muskeln denkbar. Ich kann nun dem Vordersatze, dass die Muskelfasern in den Tumoren sich mit den embryonalen Entwickelungs-Stadien der Muskelfasern in Bezug auf die Bilder decken, nicht ganz zustimmen. Im embryonalen Muskelgewebe sehen wir, dass die Muskelfasern mit zunehmendem Alter auch an Breite und Länge wachsen, und dass dementsprechend auch die Differenzirung des Protoplasmas fortschreitet, mit anderen Worten, auch die Querstreifung deutlicher wird. Es steht also die Breite der Fasern in einem gewissen directen Verhältniss zu dem Alter und der Querstreifung der Fasern. Kommen also Unterschiede in den Formen der quergestreiften Musculatur in den verschiedenen Geschwülsten vor, so könnten diese nur darin bestehen, dass dieselben verschieden hohe Entwicklungs-Stufen und verschiedenes Alter der embryonalen Muskelfasern repräsentirten. Dem ist aber thatsächlich nicht so. Die in dem zuletzt beschriebenen Tumor vorhandenen Fasern sind wohl von allen untersuchten Geschwülsten die breitesten, die Querstreifung darin ist aber trotz vorzüglicher Fixirung am allerwenigsten ausgebildet. Das Protoplasma ist vielmehr oft gleichmässig körnig, und zeigt trotz der Grösse der Fasern nur erst die ersten Anfänge der Querstreifung. Wollte man den Maassstab zur Beurtheilung solcher Fasern wirklich aus der Entwicklungs-Geschichte entlehnen, so würde man bei der Bestimmung des Alters auf grosse Schwierigkeit gerathen; ibre Grösse entspricht den Muskelfasern eines sieben- bis achtmonatlichen Embryos, während die geringe Differenzirung der contractilen Substanz auf weit jüngere Entwickelungs-Phasen zurückgeht. Ich möchte aber behaupten, dass solche quergestreiften Muskelfaseru, wie die hier beobachteten, überhaupt bei der normalen MuskelEntwickelung nicht vorkommen. Es tritt hier die Metaplasie der glatten, körnigen Muskelsubstanz in quergestreifte erst sehr spät und nur äusserst unvollkommen ein. 


\section{2}

\section{Erklärung der Abbildungen.}

Fig. Schnitt aus einem embryonalen Adeno-Sarcom (Fall 3). Der von vebrschichtigem Cyliaderepithel augekletdete Drüsengang ist von quergestreiften Huskelfasem in mehrfacher Latge unsponnen. Die Epithelien sitzen den Muskelfasen direct ohne trennende Schicht oder Membran auf.

Zeiss Apochr. homogene Oelimmersion to

Fig. 2. Oysten ans ainer Struma suprarenalis aberrata (Fall 33). Die Cysten sind theilweise von einer einfachen Lage grosser, cubischer Zellen ausgekleidet. Durch Wucherung der aushleidenden Zellen sind Sprossen oder Zellsäulen gebildet worden, die radienartig in das Lumen der Cyste hineinragen. In der linken Kcke eine Anbäkfung yon Blutpigment.

Hartnack. Object 4 Ocular 3. 